\title{
PROFESSIONAL DISCLOSURE IN THE COUNSELING PROFESSION: A REVIEW OF THE LITERATURE
}

\author{
SIMONE HIMBEAULT TAYLOR, M.A. \\ Office of Career Planning and Placement, \\ The University of Michigan, \\ Ann Arbor, Michigan
}

\author{
STEPHEN JOEL GILL, Ph.D. \\ School of Education, \\ The University of Michigan, \\ Ann Arbor, Michigan
}

\begin{abstract}
Professional disclosure is a vehicle by which clients can become informed about the services they may receive in a professional setting, including those in the allied health fields. This paper reviews the literature on professional disclosure from the viewpoints of shaping client expectations, promoting counselor accountability, and being ethically responsible. A written professional disclosure statement can be provided that satisfies these requirements.
\end{abstract}

\section{INTRODUCTION}

Ensuring that clients are thoroughly informed of any service or procedure they may utilize in a health or mental health-care situation has become a matter of increasing concern. This process of informing clients has been termed "professional disclosure" and is a concept that transcends all professions engaged in counseling, including the allied health fields. There is reason to believe that counseling in any setting is enhanced by an informed client.

Professional disclosure is a vehicle by which clients can become fully informed about the services that will be provided and through what authority. The problems surrounding this concept are complex. They involve empowerment of the client as a user of the service, increased awareness of the consumer community, and the ethical responsibility of the helping professions themselves. The purpose of this paper is to review the issues central to professional disclosure, namely, shaping client expectations, promoting counselor accounta- bility, and being ethically responsible. The professional disclosure statement will be discussed as a way of operationalizing these concepts.

The notion of public revelation by counselors arrives at an interesting time in the history of the helping professions. It is a time when questions about client protection and success in counseling are being broached more frequently. There is a public demand for procedures that will increase the likelihood that people in need of help will be able to find the appropriate services and that the quality of these services will be high.

\section{SHAPING CLIENT EXPECTATIONS}

Professional disclosure has been related to the shaping of clients' expectations for counseling. ${ }^{1}$ Promoters of professional disclosure argue that an open and complete disclosure will help shape client expectations for counseling. This, in turn, will facilitate the process and result in greater client satisfaction..$^{1-3}$ Indeed, research has established the significance of the role played by client expectations in counseling, ${ }^{6-9}$ and realistic expectations have been correlated with client satisfaction..$^{10-12}$

Levitt ${ }^{13}$ stimulated much of the subsequent expectations research in counseling when he proposed his concept of the "expectations-reality" discrepancy. He hypothesized that a discrepancy between what clients expected and what they actually experienced had an effect on the efficacy of counseling. He believed the counseling experience would be more positive when client expectations approximated reality.

Gottman and Leiblum ${ }^{14}$ postulated that a curvilinear relationship exists between client expectations and counseling outcomes, suggesting that clients with moderate expectations may improve more than those with extremely high or low expectations. Therefore, the quality of the precounseling information for clients should have an effect on the quality of the counseling process.

Frank ${ }^{15}$ stated that many potential clients did not understand the nature or purpose of the counseling process. Providing an explanation or rationale prior to counseling could prepare clients for the process and eliminate any misconceptions about the process. ${ }^{15-17}$ Clients receiving information about the counseling process have been shown to demonstrate greater improve- 
ment on process and outcome measures than did those who did not receive any information. ${ }^{18,19}$ Such findings suggest the value of inducing realistic expectations in clients through information given before counseling.

In their, study of the effects of treatment rationale and problem severity on perceptions of psychological problems and counseling approaches, Wollersheim and associates $^{10}$ found that willingness to enter counseling as well as the possession of an accurate perception of the psychological problem and treatment requirements were enhanced by providing individuals with a counseling rationale. Based on their own findings, and those of Frank $^{15}$ and others, Wollersheim et al hypothesized that providing clients with a treatment rationale would reduce the discrepancy between client-counselor expectations and thus prevent premature termination. This hypothesis suggests that client expectations could be shaped before counseling. The hypothesis also speaks to the potential for using a treatment rationale to increase client satisfaction with counseling and to provide counselor accountability.

Sobel and $\mathrm{O}^{\prime} \mathrm{Brien}^{20}$ also examined the influence of a theoretical rationale on the expectations for positive counseling results and long-term cure. They had their subjects view three tapes emphasizing three different counseling approaches and then rate each approach on its own merit. These investigators found that individuals who had not experienced counseling in the past did not necessarily have preconceived expectations for the counseling process or the counselor.

Their conclusion differs from that of Wollersheim and colleagues, ${ }^{10}$ Frank, ${ }^{15}$ and others in suggesting that clients may not have any expectations, rather than misinformed expectations. Sobel and $O^{\prime} B$ rien, ${ }^{20}$ however, charge that we should examine "the importance of an expectation for positive results induced by a specific counselor for a specific problem at the initial counseling session." Investigators agree that counselors can shape expectations before counseling and that such shaping is beneficial and valuable in facilitating counseling.

Meara and colleagues ${ }^{21}$ studied the film "Three Approaches to Psychotherapy" to compare the language the counselors and the clients used in relation to the type of therapy being utilized. This film shows three counseling theorists working with one client. Verb phrases were analyzed to determine what kind of relationship might exist between the client's speech in the interview and the counselor's prior stated intentions for the interaction. Results indicated that clients' language could be altered but not necessarily in accordance with the counselors' stated policy. These investigators concluded that counselors, to advance their understanding of counseling process and outcome, should practice two kinds of explicitness:

One is for counselors to be far more explicit than they have been about what they intend to do and to have happen in counseling with a client. The other is for investigators of the counseling process to become more explicit, in meaningful and replicable ways, than we have been about what is happening during counseling and what it is supposed to accomplish and what it does accomplish.

It is perhaps difficult to generalize on the significance of the findings because they represent only three counselors and one client. The implication of inducing expectations, even to the point of vocabulary, is clear, however. Meara et al, ${ }^{21}$ calling for this greater explicitness, addressed two issues pertinent to counseling. The first, for counselors to be more explicit with their clients, is a directive for counselors to provide clients with the information they need to make an informed choice before proceeding with counseling. This explicitness would contribute to clients' establishing realistic expectations for counseling. A second type of explicitness is a request for counselors and researchers to be accountable for what they do and how they do it. Such explicitness allows for systematic evaluation of strategies used in counseling. The result is a built-in accountability system for counselors.

Berger $^{22}$ investigated the effects four different sets of instructions for discussing personal concerns had on the productivity and satisfaction ratings of college students. Before conducting a self-interview on a tape recorder, cach subject was placcd in a group based on preliminary screening. Each group was given a description of one of the following disclosure methods: express all positive and negative feelings (feeling disclosure); analyze problems in step-by-step manner (logical disclosure); verbalize problems and concerns (placebo control); no instructions (control). After the self-interview, each subject completed a questionnaire on the value of the session. Subjects were sent identical questionnaires three weeks later. The tapes, which were scored according to the type of statement verbalized, demonstrated that different instructions resulted in different kinds of disclosure.

Berger's conclusions are particularly relevant to professional disclosure before counseling to establish basic client expectations. Subjects in the control group indicated that they would be less likely to return for counseling than did subjects in the remaining groups. This was true even when the control group was given the option of disclosing in a different way. Thus, those who had received more detailed instruction regarding counseling behavior were more receptive to returning for counseling. Based on these findings, Berger stated:

Practically, this would suggest that if a counselor wanted to interest a group of potential clients in the benefits of counseling, some type of detailed instructions or explanation would be preferable to minimal information.

It is interesting that, while not Berger's direct purpose, this study represents one of the first attempts to 
explore the value of what we term professional disclosure. Berger's conclusions cannot be extended to the general client population because he did not use a representative population in his study. Nevertheless, they strongly suggest that information and the quantity of information have a powerful impact on client satisfaction with counseling.

In a more recent study, Davidshofer and Richardson ${ }^{2}$ examined the effects of precounseling training, or professional disclosure, on reducing client anxiety and in positively influencing client attitudes and information about the counseling process. They hypothesized that clients who had experienced precounseling training would demonstrate less anxiety and more appropriate attitudes than would those who had not had the training. The subjects, clients of a college counseling center, viewed a 30-minute tape describing the counseling process. This was followed by a discussion in which subjects clarified what they had seen. Results were inconclusive regarding anxiety reduction; however, the investigators stated:

The results of this study confirm that the amount of information clients possess about the counseling process can significantly be increased by the use of a precounseling program. The significant differences noted in the ratings given by the clients' counselors further suggested that client incounseling behavior may have been positively influenced, since counselors presumably made their ratings only on observations of client behavior.

Gill and Taylor examined the effects of a counselor professional disclosure statement on client expectations, behavior, and satisfaction. Using the client population of a career planning and placement office at a large midwestern university, they found that an agency professional disclosure statement seemed to have a positive effect on client expectations. In comparing those who received a professional disclosure statement with those who had received no statement and with those who had received a general information statement (placebo control) describing available services, subjects receiving the professional disclosure statement appeared to have clearer expectations regarding both the appropriate client behavior in counseling and the potential outcomes. Client satisfaction, as rated by the clients, both immediately after the counseling session and in a follow-up survey, was higher for those given statements than for those receiving no statement, indicating a link between the sharing of precounseling information and ultimate client satisfaction with counseling.

These findings appear to substantiate the efficacy of professional disclosure in positively influencing client behavior. They support the views of those who contend that provision of precounseling information promotes accurate and positive expectations and this, in turn, contributes to client satisfaction with counseling. ${ }^{2,10,22}$

\section{PROMOTING COUNSELOR ACCOUNTABILITY}

While there exist both agreement and resistance for increased accountability in the helping professions, there is little question that the issue of accountability was born out of the consumer movement of the 1960s and 1970s. The demand from consumers for human service professionals to practice "truth in counseling" was an outgrowth of consumers' questioning the safety of their automobiles and the contents of their breakfast cereal. This thrust in consumerism, coupled with the national interest in human rights in the 1960s and 1970s, made health- and mental-health-care professions a natural target for consumer interest.

The issue, however, is complex, for one does not as easily define the contents of counseling as one does the additives in a box of cereal. ${ }^{23-26}$ In fact, one must know the contents of a particular counseling interaction before an evaluation can be made. Defining the process, however, was a problem for the relatively new and everchanging field of counseling. The flexibility in the field allowed for the growth of many diverse approaches, 27,28 but the fast growth of this new profession also contributed to lax accountability standards. Thus the counseling field had the opportunity to try unique methods and techniques but at the cost of not always being able to justify their uses. Arbuckle ${ }^{29}$ and others ${ }^{23,27,30}$ called on counselors to account to the public for a system that counselors could not always evaluate themselves. While this was a difficult issue at the time, increased consumer awareness did provide the impetus for the profession of counseling to take a serious look at itself and its methods.

Accountability can serve a multipurpose function as a vehicle for evaluating counseling from the perspective of the professional and the consumer. Professional accountability would allow counselors to justify their own strategies and identify their value to the helping professions, thus developing greater credibility for a profession that, owing to its fast growth, had lacked focus in method if not mission. ${ }^{31,32}$ Financial accountability would respond to the efficiency of counseling, delineating where and how funds were being allocated. Demonstration of effective resource utilization by the counselor could ensure that dwindling public and private funds remained available for the helping professions during times of economic restraint. Consumer accountability, an area of particular concern in this paper, would make counselors responsible for informing consumers about the product counselors offer.

Baker, ${ }^{33}$ in support of the positive aspects of accountability, stressed that accountability systems could serve as professional development models that could emphasize acquisition of skills and improved programs. He pointed out that if accountability was viewed as a process rather than an event, individual counselors, the 
profession, and consumers alike would benefit. Accountability then could serve as a self-monitoring device for the profession-a device that would keep the power of the profession within the control of the counselors rather than an outside agency. Many models for accountability are available, but the question of how counselors should manage their accountability is second to the issue that counselors should be accountable. As counselors identify and agree upon the contents of counseling they will be better equipped to justify the use of counseling in helping others.

\section{BEING ETHICALLY RESPONSIBLE}

Counselors have an ethical responsibility to inform their clients about the nature of counseling in general and the qualifications of the counselor in particular. The American Personnel and Guidance Association' ${ }^{34}$ ethical standards addresses this issue when it states that counselors should be responsible for providing accurate and sufficient information about their counseling services. The argument among counselors ranges from philosophical to semantic when defining what "providing accurate and sufficient information" means. While one may hide behind nebulous definitions, it is clear to counselors what the consequences of inaccurate or insufficient information might be. This is illustrated by Swanson' $\mathrm{s}^{35}$ humorous example:

At a recent conference, a counselor in private practice told me how shocked he was when he found out how a client had selected him. The client had gone through the yellow pages looking for a Jewish name because he had heard Jews were good counselors.

Lack of information regarding criteria for selecting a professional led this client, and no doubt many others, to use inappropriate and sometimes stereotypic attributes in choosing a counselor. Such an example provides one of the most compelling arguments for the necessity of professional disclosure.

One cannot discuss the responsibility of the counselor to provide information without discussing the consumer's responsibility as well. Where does the responsibility lie for truth in counseling? Many feel that a great part of the responsibility rests with the consumers and that, with adequate information, they can handle that responsibility. Gross, ${ }^{1}$ a strong advocate of this stance, believes that consumers can and should take greater responsibility. He stated:

Consumers have the capacity and the responsibility to protect themselves. They have experience with the service and its consequences and the potential energy to do something about it. What they need is sufficient information to make sense of their experience and to overcome their mystifying dependence.
Gross's reference to "mystifying dependence" speaks to licensure, an avenue that he is reluctant to see counselors follow. He prefers the flexibility of personal rather than institutional control, afforded through professional disclosure statements, as a means of informing the public. Others ${ }^{26.36}$ favor more formal controls, such as licensure, which set standards for the entire profession, as in psychology, medicine, and law. Still others ${ }^{4,5}$ suggest that the ideal ground will be found in the merger of licensure and professional disclosure where professional disclosure is compelled by law. Most, however, seem to agree that there is a need for increased consumer self-responsibility. Even the Nader Health Research Task Force, ${ }^{37}$ while strong advocates of licensing as a means of consumer protection, supported this stance of greater responsibility for the consumer.

Gross ${ }^{1,38,39}$ and others ${ }^{40,41}$ believe that the best protection is self-protection and that the helping professions have an obligation, independent of whether or not they are licensed, to educate the public. Given the proper information, consumers could then be as competent in choosing appropriate counselors as they are in choosing a family car.

An important view was presented by Arbuckle, ${ }^{29}$ who argued that counselors are providing information from their own perspective without considering what consumers might really want to know about counseling. Thus the information becomes the provider's version of what is needed by the consumer. He sees a danger in promoting the dissemination of information without stressing the responsibility attached to that dissemination. According to Arbuckle, by providing such information there is a maximum stress on rights and a minimum stress on responsibility on the part of the counselor, potentially resulting in an attitude, "As long as I'm honest about what I'm doing, it doesn't matter what I'm doing." Unlike Gross, who believes that consumers maintain the bulk of responsibility for their decisions, Arbuckle is wary of giving full responsibility to either consumer or provider. Thus, while there continues to be lively discussion in the profession regarding the nature of professional disclosure, there does appear to be some consensus that information should be provided to the consumer. The argument, then, appears to be one of execution rather than objection to sharing precounseling information with the client.

The next question we must ask is, "What do consumers need to know in order to make informed decisions?" London ${ }^{42}$ suggests that one of the key reasons to inform the public about counseling is to help them distinguish among the many occupational titles associated with counseling and other mental health professions. According to London, "It is not unfair to generalize that most advocates of most systems will treat most people for most problems for which most 
therapists of most other systems would treat them." If this is true, then it may be all the more reason for counselors to provide information so that clients understand their options in counseling and can choose appropriately.

Swanson ${ }^{35}$ proposed a two-factor model for informing clients that includes providing accurate and sufficient information about the counseling offered and providing guidelines for evaluating that information. The key here that has been overlooked, or at least not defined by others, is in providing the guidelines for evaluation. Winborn ${ }^{26}$ suggests the use of "honest labeling," a phrase originally reserved more for tangible products than counseling. He sees honest labeling as a way of representing one's services honestly for potential clients, beginning with describing one's competencies, counseling style, and subsequently monitoring client progress and evaluating client satisfaction.

While supportive of Winborn's descriptive approach, we would suggest that the term "honest labeling" is somewhat oxymoronic. Labeling of any sort rarely serves us justly and in this case may perpetuate rather than clarify the lay image that counseling is counseling-the very issue grappled with in professional disclosure and truth in counseling. Thus, in providing information to clients, to label oneself, for example, as a gestalt therapist is not attending to the idiosyncratic nuances of such therapy and is therefore not presenting as honest and revealing a description as one might. It is the goal of professional disclosure to go beyond labeling and provide meaningful information regarding individual counseling styles.

\section{PROFESSIONAL DISCLOSURE STATEMENT}

Gill, ${ }^{3}$ Gross, ${ }^{1}$ and Witmer ${ }^{5}$ have suggested that professional disclosure be provided to clients in the form of a written statement. Before an initial session with a counselor, the potential client would be given a statement delineating important information about the counselor and the counseling provided by that person. Gill has recommended that this statement include: the counselor's qualifications, training, and philosophy of counseling; the expected roles of client and counselor; the strategies in which the client might be asked to participate; the limitation of counseling; and the situations in which referral is recommended.

This written form of professional disclosure, aside from the uniformity and clarity ensured by a printed statement, responds to the professional counselor's need to shape client expectations, to be accountable, and to be ethically responsible. The statement can be used to influence the formation of expectations about counseling that facilitate the client-counselor interaction. ${ }^{4}$ Gross ${ }^{1}$ has referred to this influence on expectations as "demystification" because the magic and secrecy are removed from the image of counseling.

Accountability is achieved through the public revelation of counseling goals and procedures. This makes the intended work of the counselor open to scrutiny by other professionals and commits the counselor to a particular way of helping that can be evaluated. Ethical responsibilities are satisfied through the provision of "accurate and sufficient" information and by the added assurance that clients will be informed early enough to make a choice free of coercion.

The professional disclosure statement could be handed to a potential client, posted in a conspicuous place, published in a public document, or circulated to agencies that provide referral assistance. Regardless of the form and method of distribution, professional disclosure is a responsibility of anyone who helps others solve problems, make decisions, or change behavior through the counseling process.

\section{REFERENCES}

1. Gross SJ. Professional disclosure: An alternative to licensure. Personnel Guidance $J$ 1977; 55:586-588.

2. Davidshofer CO, Richardson GG. Effects of precounseling training. J Coll Stud Personnel 1981; 22:522-527.

3. Gill SJ. Professional disclosure and consumer protection in counseling. Personnel Guidance J 1982; 60:443-446.

4. Gill SJ, Taylor SH. Professional disclosure, consumerism, and counselor preparation. In: Resources in Education. Ann Arbor, Michigan: ERIC Document Reproduction Service, 1982. Access \#ED220733.

5. Witmer JM. Professional disclosure in licensure. Couns Educ Supervis 1978; 18:71-73.

6. Tinsley HEA, Benton BL. Expectations and preferences in counseling. J Coll Stud Personnel 1978; 19:537-543.

7. Tinsley HEA, Harris DJ. Client expectations for counseling. $J$ Couns Psychol 1976; 23:173-177.
8. Tinsley HEA, Workman KR, Kass RA. Factor analysis of the domain of client expectancies about counseling. I Couns Psychol 1980; 27:561-569.

9. Parham WD, Tinsley HEA. What are friends for? Students' expectations of the friendship encounter. J Couns Psychol 1980; 27:524-527.

10. Wollersheim JP, McFall ME, Hamilton SB, et al. Effects of treatment rationale and problem severity on perceptions of psychological problems and counseling approaches. J Couns Psychol 1980; 27:225-231.

11. Yuen RK, Tinsley HEA. International and American students' expectancies about counseling. J Couns Psychol 1981; 28:66-69.

12. Gladstein GA. Client expectations, counseling experience and satisfaction. J Couns Psychol 1969; 16:476-481.

13. Levitt EE. Psychotherapy research and the expectation-reality discrepancy. Psychother Theory Res Pract 1966; 3:163-166.

14. Gottman JM, Leiblum SR. How to do psychotherapy and how to evaluate it: A manual for beginners. New York: Holt, Rinehart and Winston, Inc, 1974. 
15. Frank JD. Persuasion and healing: A comparative study of psychotherapy. Rev ed. Baltimore: Johns Hopkins University Press, 1973.

16. Heitler JB. Preparatory techniques in initiating expressive psychotherapy with lower-class, unsophisticated patients. Psychol Bull 1976; 83:339-352.

17. Truax C, Wargo D. Effects on vicarious therapy pretraining and alternate sessions on outcome in group psychotherapy with outpatients. J Consult Clin Psychol 1969; 33:440-447.

18. Bednar RL, Parker CA. Client susceptibility to persuasion and counseling outcome. J Couns Psychol 1969; 16:415-420.

19. Parrino JJ. Effect of pretherapy information on learning in psychotherapy. J Abnorm Psychol 1971; 77:17-24.

20. Sobel HJ, O'Brien BA. Expectations for counseling success. $J$ Couns Psychol 1979; 26:462-464.

21. Meara NM, Pepinsky HB, Shannon JW, Murray WA. Semantic communication and expectations for counseling across three theoretical orientations. J Couns Psychol 1981; 28:110-118.

22. Berger SN. The effects of different sets of disclosure instructions on subject productivity and rated satisfaction. J Couns Psychol 1978; 25:506-513.

23. Forster JR. What shall we do about credentialing? Personnel Guidance $J$ 1977; 55:573-576.

24. Forster JR. Counselor credentialing revisited. Personnel Guidance $J$ 1978; 56:593-598.

25. Patterson CH. Theories of counseling and psychotherapy. ed 2. New York: Harper and Row, 1974.

26. Winborn BB. Honest labeling and other procedures for the protection of consumers of counseling. Personnel Guidance $J 1977$; 56:206-209.

27. Penn R. A dollar's worth of counseling and a lifetime guarantee. Personnel Guidance J 1977; 56:204-205.

28. Srebalus DJ. Rethinking change in counseling. Personnel Guidance $J 1975 ; 53: 415-421$.
29. Arbuckle DS. Consumers make mistakes too: An invited response. Personnel Guidance J 1977; 56:226-228.

30. Knapper EQ. Counselor accountability. Personnel Guidance $J$ 1978; 57:27-30.

31. Sweeney TJ. Trends that will influence counselor preparation in the 1980s. Couns Educ Supervis 1979; 18:181-189.

32. Sweeney TJ, Sturdevant AD. Licensure in the helping professions: Anatomy of an issue. Personnel Guidance $J$ 1974; 52:575-580.

33. Baker S. An argument for constructive accountability. Personnel Guidance J 1977; 56:53-55.

34. American Personnel and Guidance Association. Ethical standards. Falls Church, Virginia: American Personnel and Guidance Association, Inc., 1980.

35. Swanson JL. Counseling directory and consumer's guide: Implementing professional disclosure and consumer protection. Personnel Guidance J 1979; 58:190-193.

36. Sweeney TJ, Witmer JM. Who says you're a counselor? Personnel Guidance J 1977; 55:589-594.

37. Adams S. Through the mental health maze. Washington, D.C. Health Research Group, 1975.

38. Gross SJ. The myth of professional licensing. Am Psychol 1978; 33:1009-1016.

39. Gross SJ. Holistic perspective on professional licensure. $J$ Holistic Med 1981; 3:38-45.

40. Danish SJ, Smyer MA. Unintended consequences of requiring a license to help. Am Psychol 1981; 36:13-21.

41. Davis JW. Counseling licensure: Overkill? Personnel Guidance J 1981 ; 60:83-85.

42. London P. The modes and morals of psychotherapy. New York: Holt, Rinehart and Winston, Inc, 1964. 